Original Article

\title{
SOLUBILITY AND DISSOLUTION ENHANCEMENT OF PIOGLITAZONE USING SOLID DISPERSION TECHNIQUE
}

\section{BHUSHAN A. BHAIRAV*, LALIT R. JAGTAP, R. B. SAUDAGAR}

Department of Quality Assurance and Techniques, KCT's R. G. Sapkal College of Pharmacy, Anjaneri, Tal. Trimbakeshwar, Dist. Nashik 422213, Maharashtra, India

Email: bbhairav@gmail.com

Received: 21 May 2017, Revised and Accepted: 22 Jul 2017

\section{ABSTRACT}

Objective: To design the study to improve the solubility and hence enhance the dissolution of hydrophobic drug Pioglitazone in order to increase its bioavailability.

Methods: Solid dispersion of Pioglitazone using carriers Poloxomer 188 and HPßCD was formulated in different ratios by microwave induced fusion method. In particular, the Microwave technology has been considered in order to prepare an enhanced release dosage form for poorly water soluble drug Pioglitazone. Statistical Analysis: Their physicochemical characteristics and solubility were compared to the corresponding dispersions and marketed drug. Drug and polymer were further characterized by FTIR.

Results: The results of FTIR revealed that no chemical interaction between the drug and the polymer exist.

Conclusion: All the formulations showed a marked increase in drug release with the increase in the concentration of Poloxomer 188 and HP $\beta C D$

Keywords: Pioglitazone, Solid dispersion, Microwave Irradiation Method, Poorly water soluble drugs.

(C) 2017 The Authors. Published by Innovare Academic Sciences Pvt Ltd. This is an open access article under the CC BY license (http://creativecommons.org/licenses/by/4.0/) DOI: http://dx.doi.org/10.22159/ijcpr.2017v9i5.22326

\section{INTRODUCTION [1-3]}

The enhancement of the solubility of poorly water soluble drugs is one of the major current challenges to pharmaceutical sciences. Oral bioavailability of a drug depends on its solubility and dissolution rate, which is the rate determining step for the onset of therapeutic activity. Several techniques have been developed over the years to enhance the dissolution of the drug such as micronization, solubilization, salt formation, complexation with polymers, change in physical form, use of prodrugs, drug derivatization, alteration of $\mathrm{pH}$, the addition of surfactants etc.

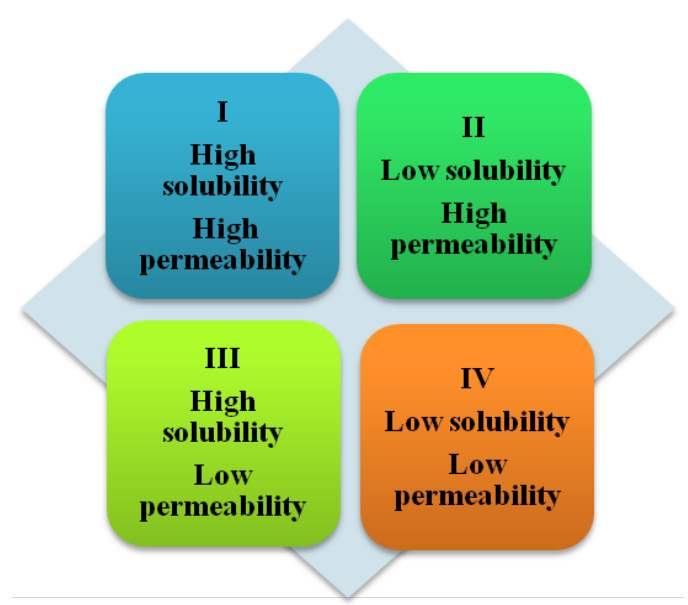

Fig. 1: Biopharmaceutical classification system (BCS)

If formulated as a solid dispersion the dissolution rate and the solubility of the active compound are often significantly increased. Contributing factors are particle size reduction, improved wetting and an enhancement of the solubility of the active compound in the solution that is formed, as the carrier dissolves. Also the carrier can have influence on the crystallization kinetics in the supersaturated solution that is formed during the process of dissolution. Several water soluble carriers such as Sodium Starch Glycolate, Microcrystalline Cellulose, Magnesium Stearate, Talc, Lactose, Poloxamer 188 etc. are used as carriers for solid dispersions. Pioglitazone is an oral rapid and short acting anti diabetic drug from the Thiazolidinedione class. It is classified as second generation Thiazolidinedione, which means that it undergoes enter hepatic circulation. As per BP, Pioglitazone is practically insoluble in water because of its poor solubility (classified as BCS class II drug).

Hence, there is a neefor development of novel solid dispersion to improve the solubility of Pioglitazone and their inI High solubility High permeability II Low solubility High permeability III High solubility Low permeability IV Low solubility Low permeability vitro characterization. The present study is an attempt to overcome the poor aqueous solubility of Pioglitazone by using solid dispersion solvent evaporation/spray drying/melt or any appropriate suitable method.

Preparative method of solid dispersion

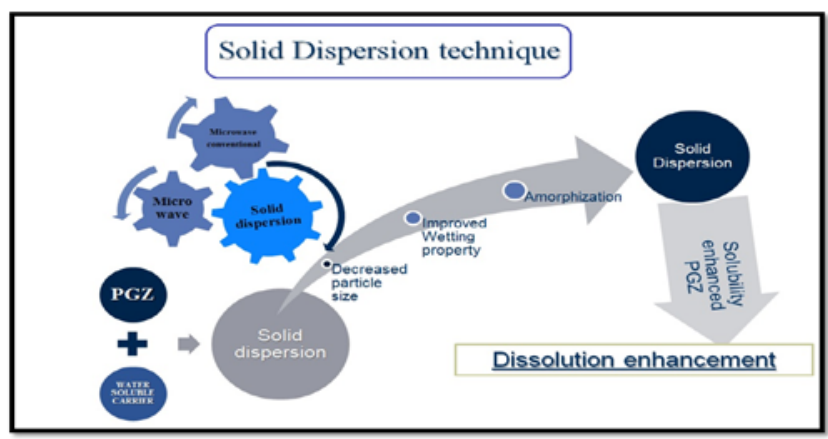

Fig. 2: Solid dispersion technique. 
Advantage and disadvantage

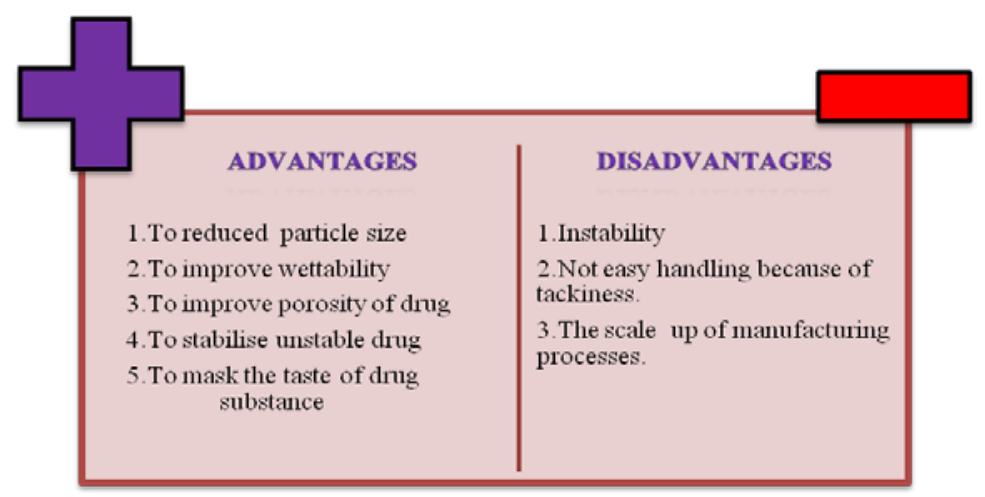

Preparation of solid dispersions by microwave asssisted method [9]



Fig. 3: Solid dispersions by microwave asssisted method

\section{MATERIALS AND METHODS}

\section{Material}

Pioglitazone was obtained as a gift sample from Cipla pharmacutical Ltd, Verna Goa. Poloxomer 188 and HP $\beta C D$ were purchased from Glenmark Pharmaceuticals, Sinnar, Nashik. All other chemicals used were of pharmaceutical grade. Method Solid dispersions were prepared by Microwave irradiation induced fusion method in three different ratios. Pioglitazone with Poloxomer 188 and HP $\beta C D$ was weighed according to different weighed ratio, as shown in table 1 and 2.

\section{Microwave induced fusion method [9]}

Solid dispersion with different ratios of Pioglitazone with Poloxomer 188 and $\mathrm{HP} \beta C D$ was prepared using the microwave induced fusion method. Firstly, Pioglitazone with Poloxomer 188 and HP $\beta C D$ was weighted in ratios of 1:1,1:3 and 1:5 W/W followed by gentle mixing for 5 min using a mortar and pestle. A fixed amount of these mixtures were subjected to microwave for $5 \mathrm{~min}, 6 \mathrm{~min}$ and $7 \mathrm{~min}$ at a constant chosen power of $700 \mathrm{~W}$ in a microwave instrument. Only one beaker at a time was placed inside the microwave. The samples were exposed in the microwave for a predetermined time interval. The beaker was Drug+polymer (Poloxamer 188) mixtures were dissolved in methanol in the ratio 1:1, 1:3, 1:5. Small amound of a mixture of Organic solvent (methanol) in a specified proportion 1:1, $1: 3,1: 5$. Is add into a reaction mixture.

The mixture is reacted for short time of about 1-2 minute. At $600 \mathrm{~W}$ in the microwave oven. The obtained solid dispersions were air dried in an oven at $40^{\circ} \mathrm{C}$. prepared solid dispersion passed through $120 \#$ sieve to obtained sized solid dispersion. The solid dispersion is stored in desiccatore until use. Then placed at room temperature for solidification. Solid dispersions were collected and stored in the desiccators for $24 \mathrm{hr}$ and then the product was pulverized using a mortar and pestle. The pulverized powders were passed through an $80 \#$ sieve.

\section{Mechanism of microwave heat}

CONVENTIONAL

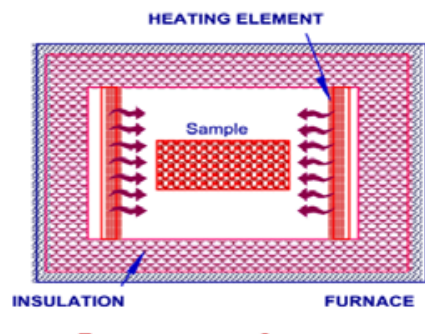

Energy transfer

External heating source

Heat Flow: outside to inside

Material independent

Energy losses
MICROWAVE

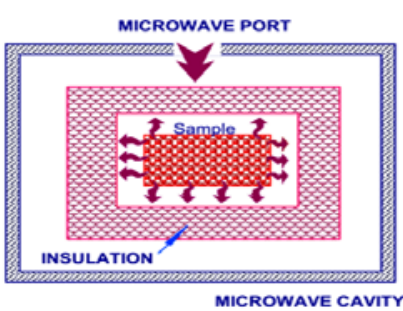

Energy conversion

Internal heating

Inside to outside

Material dependent

Highly efficient

Fig. 4: Mechanism of microwave heat 
Table 1: Formula for the preparation of pioglitazone solid dispersion with poloxamer 188

\begin{tabular}{lll}
\hline S. No. & Composition & Ratio $(\mathbf{w} / \mathbf{w})$ \\
\cline { 2 - 3 } & Drug: polymers & $1: 1$ \\
\hline 1 & Pioglitazone: Poloxamer 188 & $1: 3$ \\
3 & Pioglitazone: Poloxamer 188 & $1: 5$ \\
\hline
\end{tabular}

Table 2: Formula for the preparation of pioglitazone solid dispersion with HPßCD

\begin{tabular}{|c|c|c|}
\hline \multirow[t]{2}{*}{ S. No. } & Composition & \multirow[t]{2}{*}{ Ratio (w/w) } \\
\hline & Drug: polymers & \\
\hline 1 & Pioglitazone: HP $\beta C D$ & $1: 1$ \\
\hline 2 & Pioglitazone: HP $\beta C D$ & $1: 3$ \\
\hline 3 & Pioglitazone: $\mathrm{HP} \beta C D$ & $1: 5$ \\
\hline
\end{tabular}

Tertiary solid dispersion $\{\mathrm{MW}\}$

Table 3: Formula for the preparation of pioglitazone solid dispersion with poloxamer188: HPßCD

\begin{tabular}{lll}
\hline S. No. & Composition & Ratio (w/w) \\
& Drug: Polymers & $1: 1$ \\
1 & Pioglitazone: Poloxamer 188: HP $\beta C D$ & $1: 3$ \\
2 & Pioglitazone: Poloxamer 188: HP $\beta C D$ & $1: 5$ \\
3 & Pioglitazone: Poloxamer 188: HP $\beta C D$ & \\
\hline
\end{tabular}

Physical mixture

Table 4: Formula for the preparation of pioglitazone solid dispersion with poloxamer 188

\begin{tabular}{lll}
\hline S. No. & Composition & Ratio (w/w) \\
\cline { 2 - 3 } & Drug: polymers & $1: 1$ \\
\hline 1 & Pioglitazone: Poloxamer 188 & $1: 3$ \\
2 & Pioglitazone: Poloxamer 188 & $1: 5$ \\
3 & Pioglitazone: Poloxamer 188 & \\
\hline
\end{tabular}

\section{Melting point determination of pioglitazone [42]}

Melting point of Pioglitazone was determined melting point apparatus. Solubility studies $[11,12,18]$

Solubility studies were performed according to the method described by Higuchi and Connors. The saturation solubility of drug and SDs with Poloxomer 188 and $\mathrm{HP} \beta C D$ respectively, (1:1, 1:3 and 1:5 w/w) in water was determined by adding an excess of drug and SDs to $50 \mathrm{ml}$ distilled water in conical flask and were rotated in a orbital shaking incubator for $72 \mathrm{hr}$. at $370 \mathrm{C} \pm 0.50 \mathrm{C}$. The saturated solutions were filtered through a $0.45 \mu \mathrm{m}$ membrane filter, suitably diluted with water and analyzed by Jasco V-630 UV spectrophotometer at $269 \mathrm{~nm}$.

\section{In vitro dissolution studies [9]}

Dissolution studies on Pioglitazone (Plain drug), as well as the Solid dispersions, were performed using the USP tablet dissolution test apparatus II with Samples equivalent to $15 \mathrm{mg}$ of Pioglitazone was hold in Muslin cloth and then added to $900 \mathrm{ml}$ of phosphate buffer $\mathrm{pH} 7.4$ at $37 \pm 0.5{ }^{\circ} \mathrm{C}$ and stirred at $50 \mathrm{rpm} .5 \mathrm{ml}$ aliquots were withdrawn at time interval of 5, 15, 30, 45, $60 \mathrm{~min}$ and filtered through Whatman's (No. 41) filter paper. An equal volume of fresh dissolution medium was replaced to maintain the volume of dissolution medium. The filtered samples were analyzed spectrophotometrically at $269 \mathrm{~nm}$. Cumulative percentage of the labeled amount of drug released was calculated.

\section{Fourier transform infrared spectroscopy (FTIR)}

The KBr discs of Pioglitazone, Poloxomer 188 and HP $\beta C D$ and finalized solid dispersions were prepared using electrically operated $\mathrm{KBr}$ Press Model SHIMADZU FTIR-5300 Fourier transform spectrophotometer was used to record IR spectra of the prepared discs, to confirm any interaction of Pioglitazone with other excipients of dispersion.

\section{RESULTS}

\section{Melting point}

The melting point of pioglitazone was found to be $187-192{ }^{\circ} \mathrm{C}$

\section{Solubility}

Practically insoluble in water; very slightly soluble in methanol and $0.1 \mathrm{~N} \mathrm{HCL}$; practically insoluble in ethanol (95 per cent). Solutions of Pioglitazone was prepared in methanol and scanned between 200$400 \mathrm{~nm}$ using UV spectrophotometer showed a peak at wavelength $269.0 \mathrm{~nm}$. However, keeping in mind the probable concentrations likely to be encountered while carrying out In vitro release studies and considering the predicted theoretical $\lambda \max$ involved, the working $\lambda$ max was decided as $269.0 \mathrm{~nm}$.

Table 5: Standard calibration curve data of pioglitazone in methanol at $269 \mathrm{~nm}$

\begin{tabular}{lll}
\hline S. No. & $\begin{array}{l}\text { Concentration } \\
\text { (ppm) }\end{array}$ & Absorbance at 249 $\mathbf{~ n m}$ \\
\hline 1. & 2 & 0.126 \\
2. & 4 & 0.245 \\
3. & 6 & 0.356 \\
4. & 8 & 0.416 \\
5. & 10 & 0.483 \\
6. & 12 & 0.568 \\
7. & 14 & 0.672 \\
8. & 16 & 0.915 \\
\hline
\end{tabular}




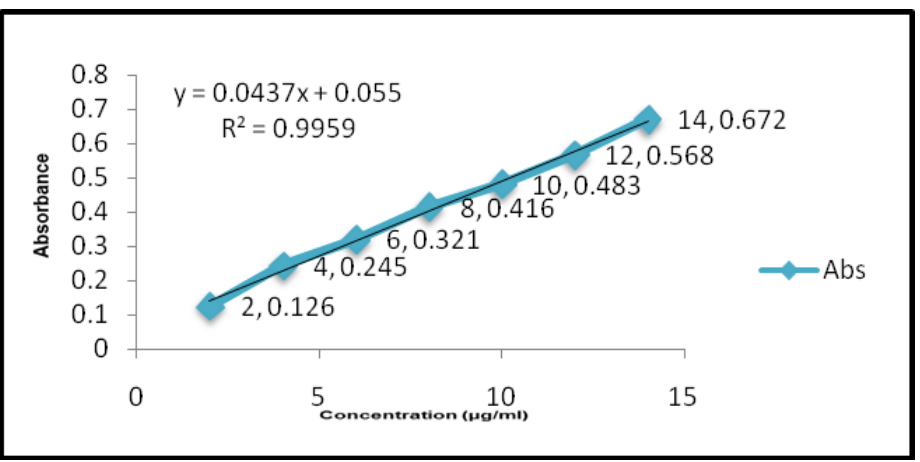

Fig. 5: Calibration curve of PGZ in methanol at $269.0 \mathrm{~nm}$

Table 6: Result of phase solubility study

\begin{tabular}{llllll}
\hline S. No. & Formulation code & Drug & Polymer & Ratio & Solubility (mg/ml) \pm SD \\
\hline 1. & Drug & PGZ & ---- & ---- & 0.045 \\
2. & SD1 & PGZ & PLX 188 & $1: 1$ & $51.69 \pm 0.014$ \\
3. & SD2 & PGZ & PLX 188 & $1: 3$ & $27.30 \pm 0.003$ \\
4. & SD3 & PGZ & PLX 188 & $1: 5$ & $22.57 \pm 0.008$ \\
5 & SD1 & PGZ & HPßCD & $1: 1$ & $20.51 \pm 0.006$ \\
6 & SD2 & PGZ & HPßCD & $1: 3$ & $17.03 \pm 0.011$ \\
7. & SD3 & PGZ & HPßCD & $1: 5$ & $13.82 \pm 0.006$ \\
8. & SD1 & PGZ & PLX 188+HPßCD & $1: 1: 1$ & $19.44 \pm 0.008$ \\
9. & SD2 & PGZ & PLX 188+HPßCD & $1: 3: 1.5$ & $22.75 \pm 0.0089$ \\
10. & SD3 & PGZ & PLX 188+HPßCD & $1: 5: 2.5$ & $11.5 \pm 0.0057$ \\
11. & SD4 & PGZ & PLX 188+HPßCD & $1: 2: 3$ & $18.46 \pm 0.01$ \\
12. & PM1 & PGZ & PLX 188 & $1: 1$ & $42.44 \pm 0.0088$ \\
13. & PM2 & PGZ & PLX 188 & $1: 3$ & $43.64 \pm 0.011$ \\
14. & PM3 & PGZ & PLX 188 & $1: 5$ & $41.05 \pm 0.008$ \\
\hline
\end{tabular}

\section{Percentage yield}

The production yield of solid dispersion prepared by Microwave assisted method was found to be $80 \%$.
Any loss in yield can be attributed to the product remaining adhered to the walls of the mortar which could not be retrieved the results of Percentage Yield are shown in (table 24).

Table 7: Result of percentage yield

\begin{tabular}{lllll}
\hline S. No. & Drug & Polymer & Ratio & Percentage yield \\
1. & PGZ & PLX 188 & $1: 1$ & $80 \%$ \\
2. & PGZ & PLX 188 & $1: 3$ & $85 \%$ \\
3. & PGZ & PLX 188 & $1: 5$ & $76.6 \%$ \\
\hline
\end{tabular}

Dissolution study of solid dispersion with pure drug

Table 8: Dissolution study of pure drug and PGZ solid dispersion

\begin{tabular}{lll}
\hline Time (min) & (\%) drug release \pm SD & PGZ solid dispersion \\
\cline { 2 - 3 } & Marketed drug & $28.25 \pm 0.088$ \\
05 & $28.05 \pm 0.012$ & $54.54 \pm 0.017$ \\
15 & $52.75 \pm 0.015$ & $64.84 \pm 0.084$ \\
30 & $64.06 \pm 0.014$ & $88.01 \pm 0.0115$ \\
45 & $86.68 \pm 0.008$ & $98.60 \pm 0.115$ \\
60 & $94.23 \pm 0.014$ & \\
\hline
\end{tabular}

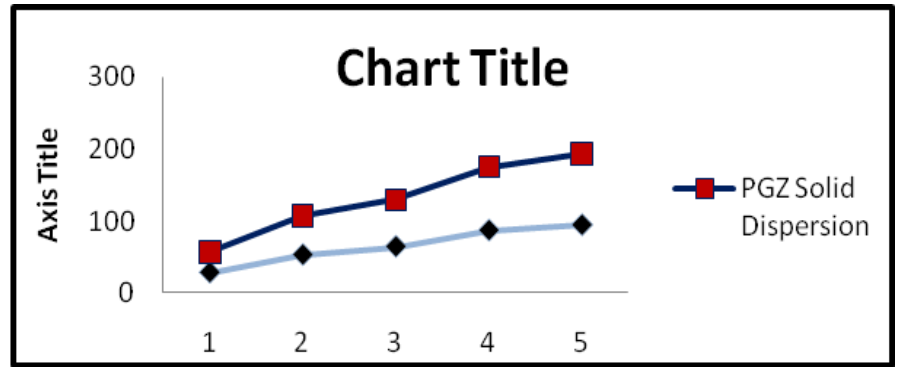

Fig. 6: Dissolution profiles of marketed drug and PGZ solid dispersion 


\section{FT-IR spectroscopic studies}

FTIR was performed on Pioglitazone, Poloxomer 188 and HP $\beta C D$, a solid dispersion of Pioglitazone with all carriers as per fig. 6, table 7 and fig. 7, table 8 resp. The IR spectra of solid dispersion showed all the principal IR absorption peak of Pioglitazone $3251 \mathrm{~cm}-1,2928$ $\mathrm{cm}-1,1687 \mathrm{~cm}-1,1314 \mathrm{~cm}-1,1243 \mathrm{~cm}-1$, and $849 \mathrm{~cm}-1$. FTIR of a solid dispersion of drug and all carriers shows that all the peaks of drug and carrier as it is and the drug is present in free form. This indicates that there is no interaction in between Pioglitazone and the entire carrier employed in solid dispersion.

The obtained spectrum was compared with the spectrum that was in literature to confirm the authenticity of the given sample. These results suggested that there was no interaction between Pioglitazone and Poloxomer 188 and HPßCD.

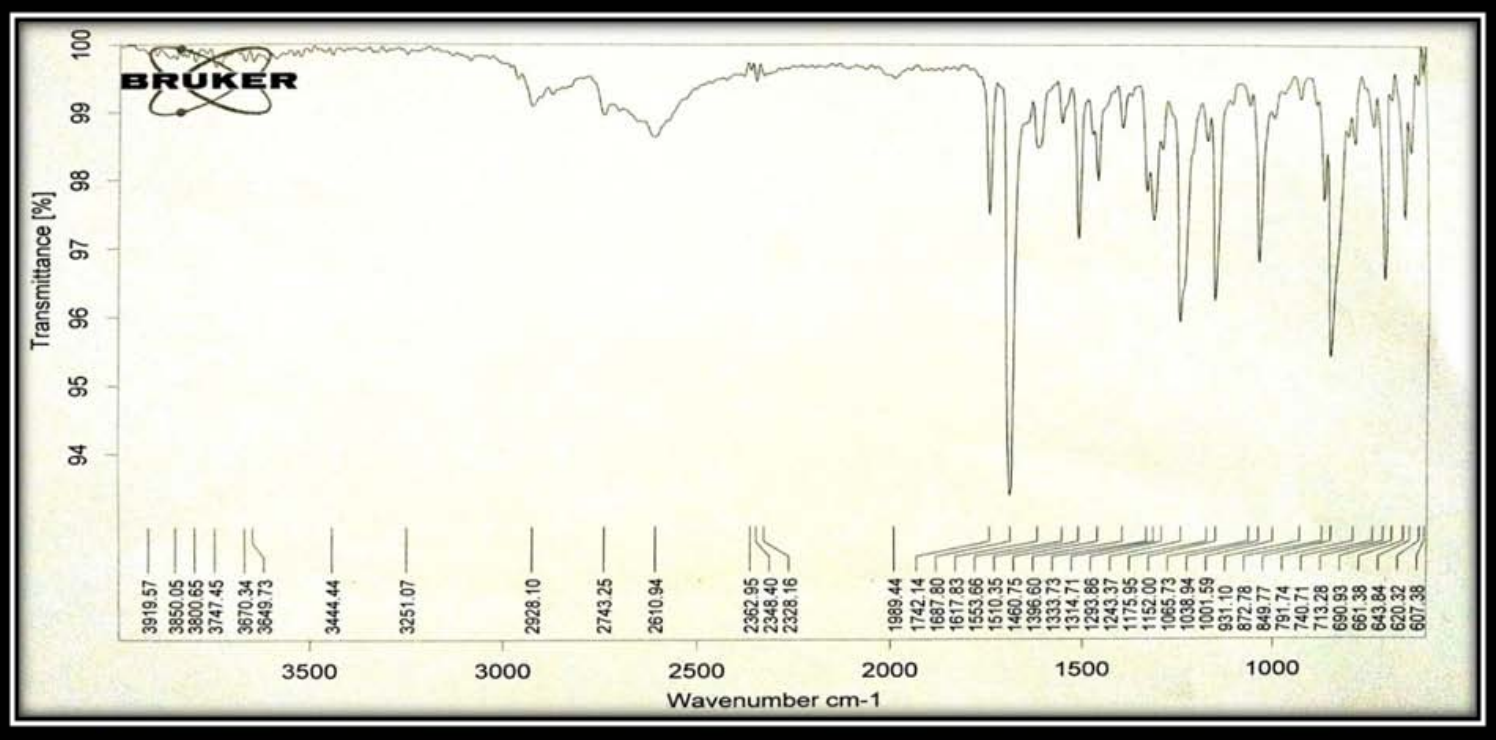

Fig. 7: FT-IR spectrum of pioglitazone

Table 9: Functional groups with frequencies present in FTIR spectrum of PGZ

\begin{tabular}{llll}
\hline S. No. & Functional group & Standard frequency (cm-1) & Observed IR frequency (cm-1) \\
\hline 1. & C-O fingerprint region (Aliphatic) & $600-1400$ & 849 \\
2. & C-S Stretching & $1136-1347$ & 1243 \\
3. & C-N Stretching & $1080-1360$ & 1314 \\
4. & C=O Streching (Amide) & $1670-1820$ & 1687 \\
6. & C-H Stretching (Aromatic) & $3000-3100$ & 2928 \\
7. & N-H Stretching (Amide) & $3310-3140$ & 3251 \\
\hline
\end{tabular}



Fig. 8: FT-IR spectrum of PGZ+POLOXAMER 188 (PM) 


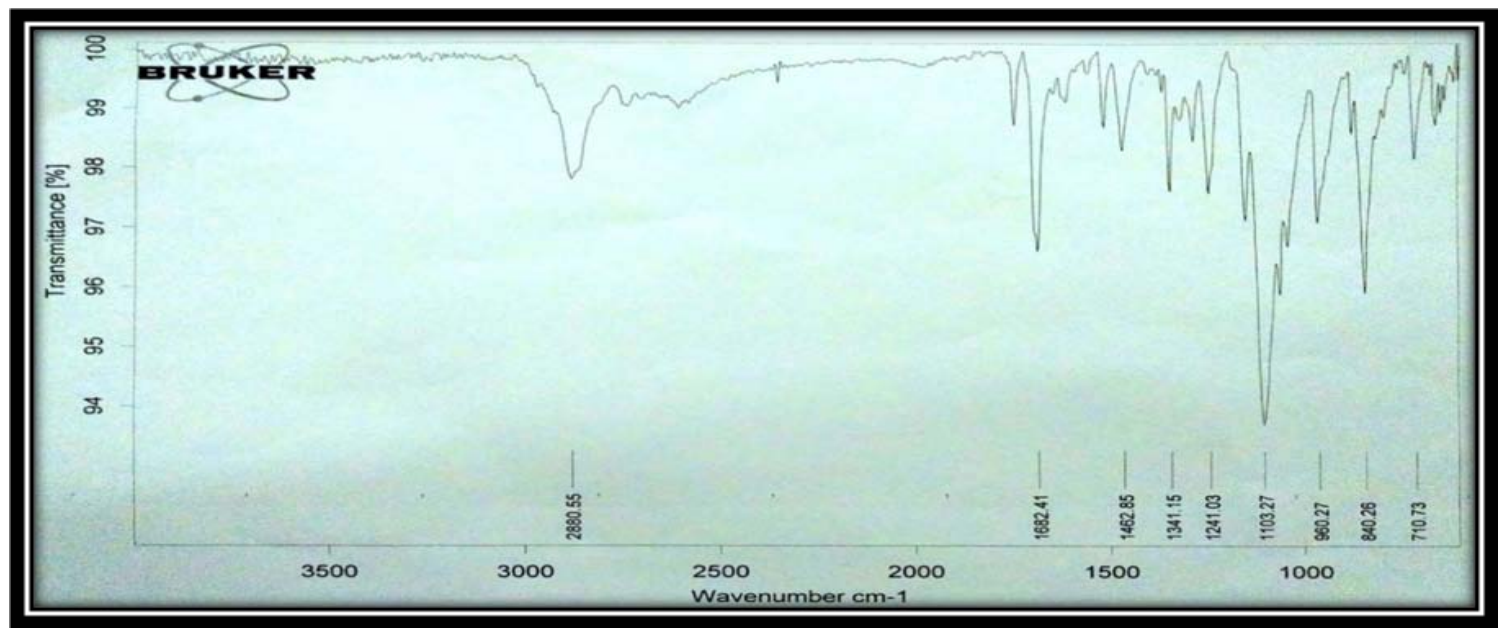

Fig. 9: FTIR spectra of pioglitazone+poloxamer 188SD (MW)

\section{Powder X-Ray diffraction}

The SD was studied for prediction of crystallinity. The PXRD Pattern of PGZ is shown in fig. 21. Based on the diffractogram it can be suggested that PGZ is present in its amorphous form since it exhibits several well-defined peaks at a diffractogram angle of $2 \theta$. The strong peak at $2 \theta$ of 22.762 was a highly intense peak with $100 \%$ intensity indicating the presence of amorphous PGZ.

PGZ: PLX 188(MW) fig. 22, XRD diffraction pattern revealed that the functional peak of PGZ was of low intensity and showing a characteristic peak of PLX 188 in the solid dispersion at $2 \theta$ of 22.520 indicating the presence of PGZ in the crystalline state within the PLX 188.

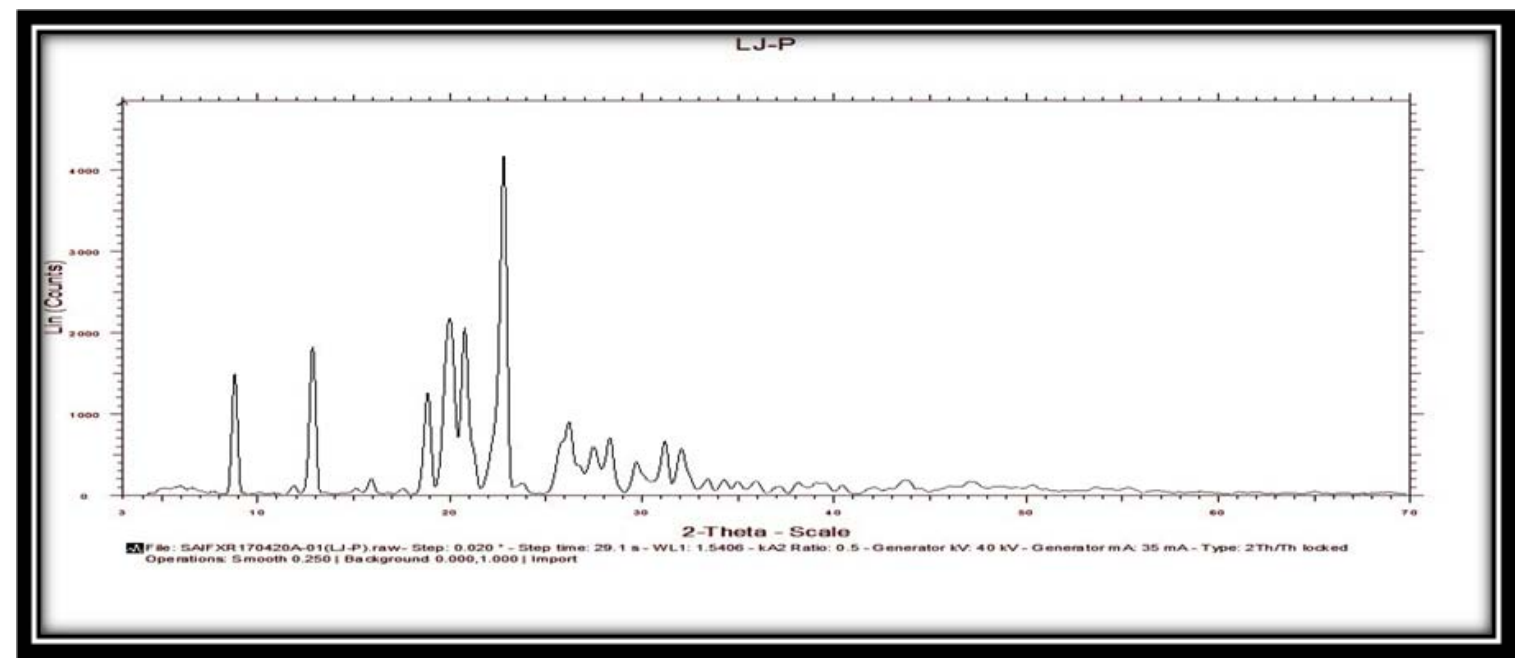

Fig. 10: PXR-diffractogram of PGZ

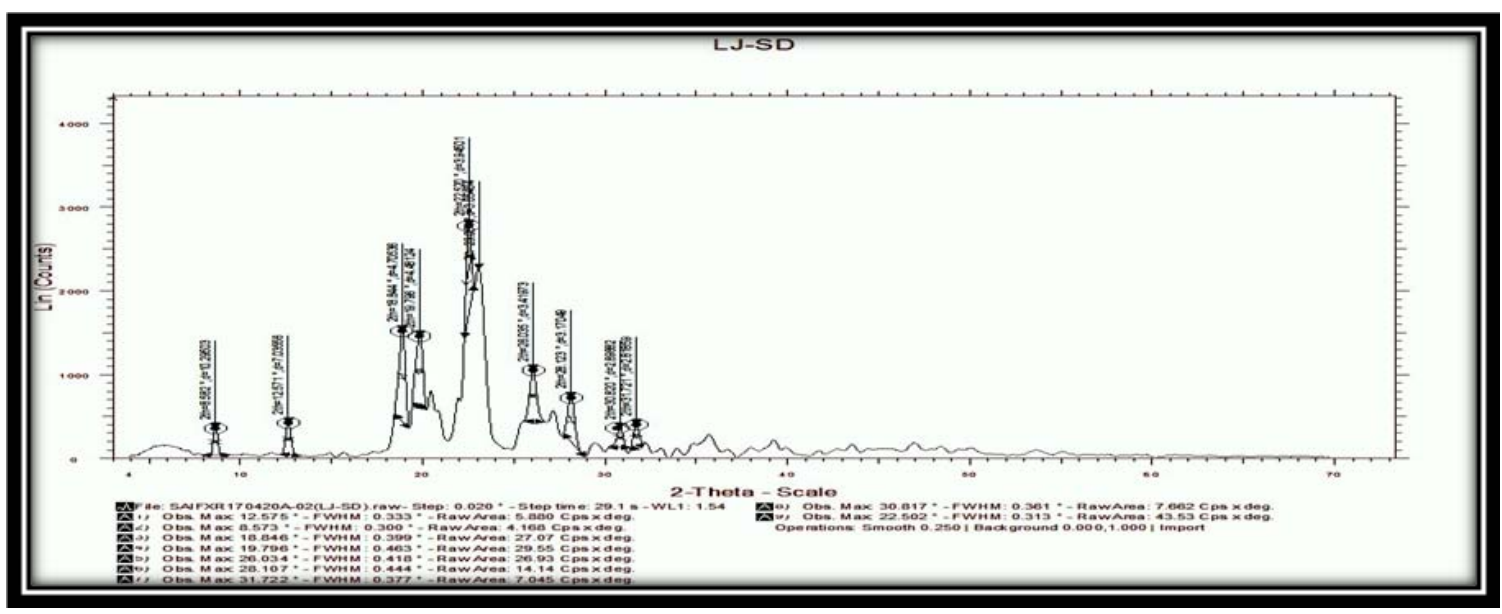

Fig. 11: PXR-diffractogram of PGZ: PLX 188(MW) 


\section{Differential scanning calorimetry}

The amorphous form of drug in spite of having high solubility is high energy unstable form of the drug which tends to re-crystallize owing to thermodynamic driving force leading to product failure. One approach employed to prevent or slow the transformation from amorphous to the crystalline state is the addition of compatible polymers. Polymers are thought to improve the stability of amorphous solids to crystallization by increasing the glass transition temperature $(\mathrm{Tg})$ of the resultant $\mathrm{SD}$, resulting in a decrease in mobility of the drug molecules, and through the formation of drug-polymer specific interactions which act to disrupt selfassembly. Drug-polymer specific interactions are thought to be of particular importance and needed to be analyzed by using Differential Scanning Calorimetry.

Differential scanning calorimetry studies were carried out in order to evaluate the ability of the polymer to stabilize amorphous form of the drug in SD. DSC thermograph of PGZ is shown in fig. 23 which shows melting endotherm at $197.790 \mathrm{c}$ i.e. melting point and the amorphous state of the drug.

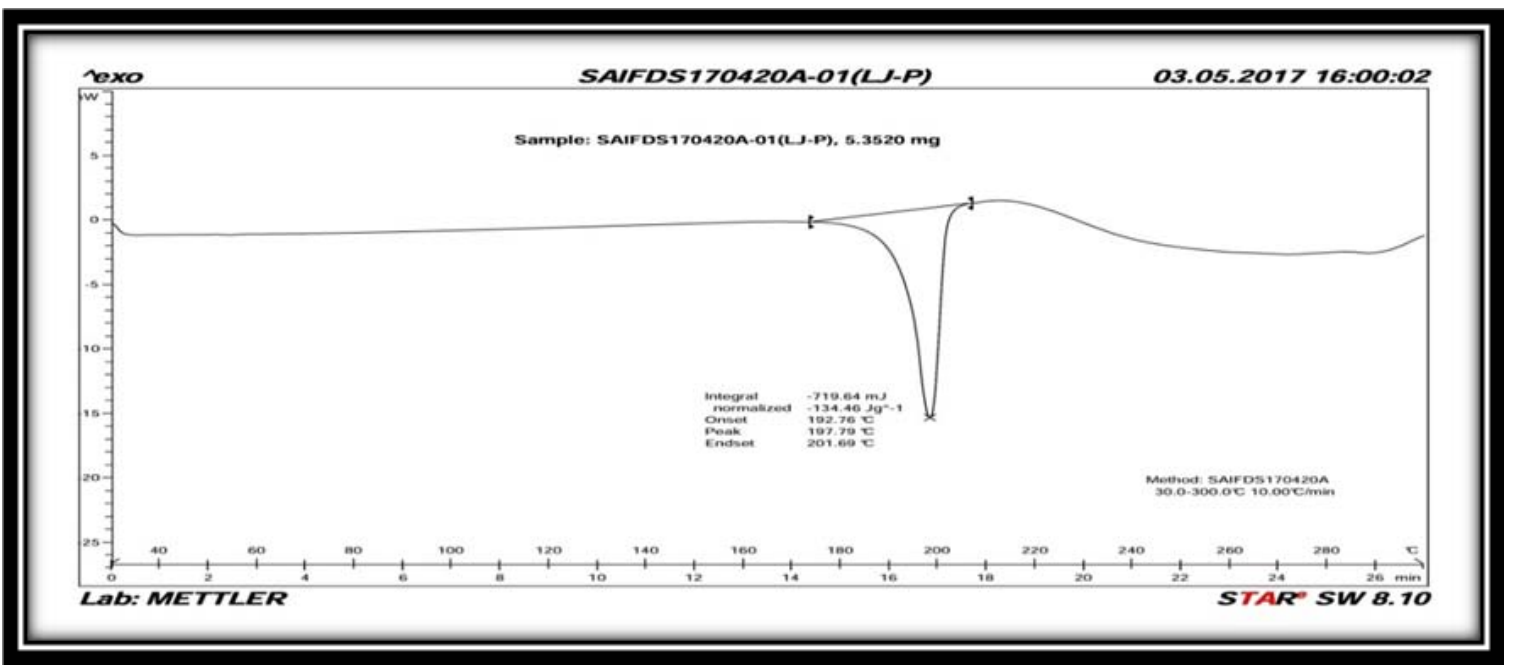

Fig. 12: DSC thermograph of PGZ

DSC thermograph of PGZ: PLX 188 (MW) is shown in fig. 24 indicating the formation of stable crystalline SD investigated by a decline in melting endotherm of PLX 188 from $50.830 \mathrm{c}$ to $60.780 \mathrm{c}$ and increase in melting endotherm of PGZ from $189.710 \mathrm{c}$ to $202.620 \mathrm{c}$.

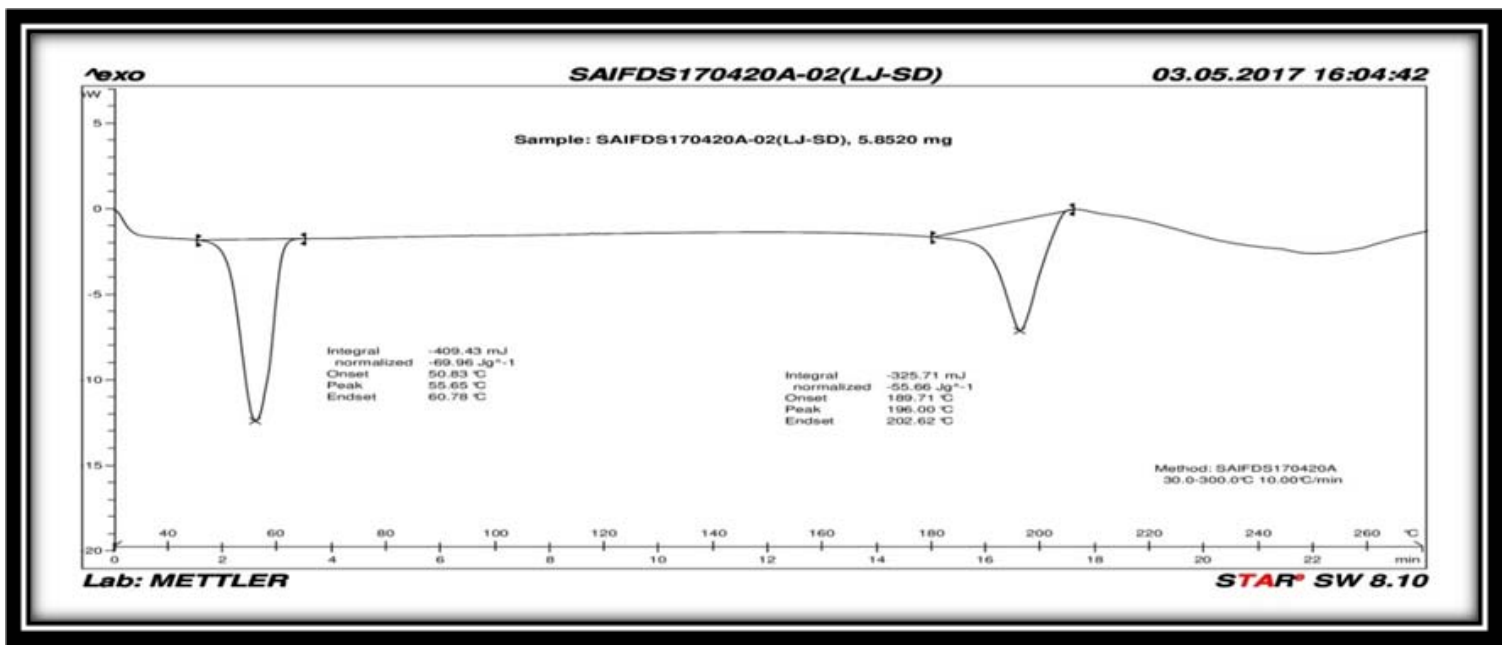

Fig. 13: DSC thermograph of PGZ: PLX 188(MW)

\section{DISCUSSION}

There is an enhancement of the solubility rate if Pioglitazone by solid dispersion with Poloxamer 188 prepared by Microwave irradiation method. The binary system found to be better solubility enhancement (11.46 fold) as compared to a ternary system and Physical Mixture. It was found that in the binary system there is 11.46 fold increasing solubility in from the FT-IR, DSC, PXRD characterization it can be concluded that the Pioglitazone has been converted into an amorphous form in solid dispersion and which is mainly responsible for solubility and dissolution enhancement.

\section{ACKNOWLEDGEMENT}

The authors are very thankful to the Trustees of KCT's R. G. Sapkal College of Pharmacy, Anjaneri, Tal. Trimbakeshwar, Dist. Nashik422213, Maharashtra, India. for making the facilities available to us. We are also thankful to Ciplapharmacutical Ltd, Verna Goa for providing the gift sample.

\section{CONFLICT OF INTERESTS}

Declare none 


\section{REFERENCES}

1. Kumar A, Sahoo SK. Review on solubility enhancement techniques for hydrophobic drugs. Pharm Globale 2011;3:1-7.

2. Urbanetz NA, Lippold BC. Solid dispersions of nimodipine and polyethylene glycol 2000:dissolution properties and physicochemical characterization. Eur J Pharm Biopharm 2005;59:107-18.

3. Leuner C, Dressman J. Improving drug solubility for oral delivery using solid dispersions. Eur J Pharm Biopharm 2000;50:47-60.

4. Amidon GL, Lennernas H, Shah, Crison VP JR. A theoretical basis for a biopharmaceutics drug classification: the correlation of in vitro drug product dissolution and in vivo bioavailability. Pharm Res 1995;12:413-20.

5. FDA. Guidance for Industry, Waiver of in vivo bioavailability and bioequivalence studies for immediate-release solid oral dosage forms based on a biopharmaceutics classification system; 2000. Available from: http://www.fda.gov/ downloads/Drugs/GuidanceComplianceRegulatoryInformation /Guidances/ucm070246.pdf. [Last accessed on 10 Apr 2017]

6. EMEA. Guideline on the investigation of bioequivalence; 2010. Avaiable from: http://www.ema.europa.eu/docs/enGB/ documentlibrary/Scientificguideline/201

0/01/WC500070039.pdf. [Last accessed on 10 Apr 2017]

7. WHO. Multisource (generic) pharmaceutical products: guidelines on registration requirements to establish interchangeability. Annex. 7, WHO Technical Report Series 937; 2006. Available from: http://whqlibdoc.who.int/trs/WHO TRS 937 eng.pdf. [Last accessed on 10 Apr 2017]

8. Yohei $\mathrm{K}$, Koichi W. Formulation design for poorly water-soluble drugs based on biopharmaceutics classification system: basic approaches and practical applications. Int J Pharm 2011;420:1-10.

9. Jaydeep N Dusane. Solubility Enhancement of glipizide by using microwave assisted solid dispersion method; 2016. p. 68-80.

10. Horter D, Dressman JB. Influence of physicochemical properties on dissolution of drugs in the gastrointestinal tract. Adv Drug Delivery Rev 2001;46:75-87.

11. Indian Pharmacopoeia. Government of ministry of health and family welfare. Indian Pharmacopoeia Commission, Ghaziabad 2010;3:147, 185-198, 1219-1220.

12. United State Pharmacopoeia. Water-Solid interaction of pharmaceutical systems, the official compendia of the standard; 2008. p. 710.

13. British Pharmacopoeia. London The stationary office, Published by the Stationary office on behalf of the medicines and healthcare products. Solubility Definition; 2009. p. 2208.

14. Sanjay Batra. Formulation and evaluation of sustain release matrix tablets of pioglitazone. Int J Pharm Sci Lett 2015;4:1-22.

15. Patrick J Sinko. Solubility and Distribution Phenomenon, Martin"s Physical Pharmacy and Pharmaceutical Sciences. Sixth Edition; 2011. p. 182-96.

16. Remington. The Science and Practice of Pharmacy. 21st edition. Vol. I-II. Published by Wolters Kuwar (India) Pvt. Ltd: New Delhi; 2015. p. 223, 903-914.

17. James Swarbrick. Encyclopedia of Pharmaceutical Technology. $2^{\text {nd }}$ edition. Vol. 1,3; 717-28, 2458-65, 2701-12.

18. Qiu. Developing Solid oral dosage form, Pharmaceutical Theory and Practice. Academic Press: Part I, II, III; 2006. p. 3-22, $87-$ 124, 125-46, 319-40, 501-18.

19. Patel N. Techniques to improve the solubility of poorly soluble drugs. Int J Pharm Life Sci Rev 2012;3:1459-69.

20. Sarmento B, Vasconcelose T. Solid dispersion as a strategy to improve oral bioavailability of poorly water soluble drugs. Adv Drug Delivery Rev 2007;12:1068-75.

21. Beom Jin Lee. Current trends and future perspectives of a solid dispersion containing poorly water soluble drugs. Eur J Pharm Biopharm Rev 2013;85:799-813.

22. Jared AB, Taylor SL. Evaluation of amorphous solid dispersion properties using thermal analysis techniques. Advance Drug Delivery Review 2012;64:396-421.

23. Van Drooge DJ. Characterization of the molecular distribution of drugs in glassy solid dispersions at the nanometer scale, using differential scanning calorimetry and gravimetric water vapour sorption techniques. Int J Pharm 2006;310:220-9.

24. Dressman J. Drug solubility: how to measure it, how to improve it. Adv Drug Delivery Rev 2007;59:531-2

25. Taral Mayur N. Solubility enhancement of atorvastatin calcium by using microwave assisted solid dispersion preparation method. Int J Pharm Res Allied Sci 2015;4:51-6.

26. Taylor SL, Baird JA. Evaluation of amorphous solid dispersion properties using the thermal analytical technique. Adv Drug Delivery Rev 2012;64:396-421.

27. Chiou WL, Riegelman S. Preparation and dissolution characteristics of several fast-release solid dispersions of griseofulvin. J Pharm Sci 1969;58:1505-10.

28. Sajid M, Choudhary V. Solubility enhancement methods with the importance of hydrotropy. J Drug Delivery Thera 2012;6:96-101.

29. Kogermann K, Penkina A. Dissolution testing of amorphous solid dispersion. Int J Pharm 2013;444:40-6.

30. Arun Kumar Dash, Suchismita Jena, Sudhir Kumar Sahoo. Study of the effect of $\mathrm{pH}$ on pioglitazone by UV spectroscopy and its estimation in bulk and pharmaceutical dosage forms. Reference ID: PHARMATUTOR-ART-1040.

31. S Sayed, A Thomas. RP-HPLC method development for determination of Pioglitazone hydrochloride from tablets. J Pharm Res 2009;2:1479-80.

32. Jedlieka, J Klime, Grafnetterova T. Reversed-phase HPLC methods for purity test and assay of pioglitazone hydrochloride in tablets. Pharmazie 2004;59:178-82.

33. Radhakrishna T, Sreenivas RD. Determination of poglitazone hydrochloride in bulk and pharmaceutical formulations by HPLC and MEKC methods. J Pharma Biomed Anal 2002;29:593.

34. Pradeepthi J, Masthanamma SK. A validated spectrophotometric method for determination of determination of Azilsartan medoxomil in pharmaceutical dosage form. J Sci Res Pharm 2013;4:7-10.

35. Takeda Pharmaceuticals, Azilsartan Medoxomil (TAK 491), NDA 200-796. Center for drug evaluation and research. Application number 2007960rig1s000, Chemistry Review(s); 2011.

36. Amar. The Modified natural carrier in solid dispersion for enhancement of solublity of poorly water soluble drugs. J Drug Delivery Thera 2014;4:111-6.

37. Kathy Z, Cheng WM. Azilsartan medoxomil a new angiotensin receptor blocker. Clin Thera 2011;33:1577-89.

38. Yasir M, Asif M. Biopharmaceutical classification system: an account. Int J Reprod BioMed 2010;2:1681-90.

39. Leuner C, Dressman J. Improving drug solubility for oral delivery using solid dispersions. Eur J Pharm Biopharm 2000;50:47-60.

40. Sarmento B, Vasconcelose T. Solid dispersion as strategy to improve oral bioavailability of poorly water soluble drugs. Adv Drug Delivery Rev 2007;12:1068-75.

41. Laxmikant Zawar. Microwave induced solid dispersion as a novel technique for enhancing the dissolution rate of repaglinide. Adv Pharmacol Pharm 2013;1:95-10.

42. Craig QM. The mechanisms of drug release from solid dispersions in water soluble polymers. Int J Pharm 2002; 231:131-44.

43. Serajuddin TM. Solid dispersion of poorly water soluble drug: early promises. Subsequent Problems Recent Breakthroughs 1999;88:1058-67.

44. Gines J, Arias M. Thermal investigation of crystallization of polyethylene glycols in solid dispersion containing oxazepam. Int J Pharm 1996;143:247-53.

\section{How to cite this article}

- $\quad$ Bhushan A Bhairav, Lalit R Jagtap, RB Saudagar. Solubility and dissolution enhancement of pioglitazone using solid dispersion technique. Int J Curr Pharm Res 2017;9(5):186-193. 